\title{
Immunohistochemical Characterization of Rapid Dentin Formation Induced by Enamel Matrix Derivative
}

\author{
Y. Nakamura, ${ }^{1}$ I. Slaby, ${ }^{2}$ K. Matsumoto, ${ }^{1}$ H. H. Ritchie, ${ }^{3}$ S. P. Lyngstadaas ${ }^{4}$ \\ ${ }^{1}$ Department of Endodontics, School of Dentistry, Showa University, 2-1-1, Kitasenzoku, Ohta-ku, Tokyo 145-8515, Japan \\ ${ }^{2}$ Biora AB, Medeon Science Park, Malmö, SE 205-12, Sweden \\ ${ }^{3}$ Department of Cariology, Restorative Sciences and Endodontics, School of Dentistry, University of Michigan, Ann Arbor, Michigan 48109-1078, \\ USA \\ ${ }^{4}$ Oral Research Laboratory, Faculty of Dentistry, University of Oslo, PO box 1109, Blindern, Oslo NO-0317, Norway
}

Received: 28 June 2003 / Accepted: 06 November 2003 / Online publication: 20 May 2004

\begin{abstract}
The purpose of this study was to examine the pulpal expression of dentin-related proteins during enamel matrix derivative (EMD)-induced reparative dentin formation in a pulpotomy model in pig incisors. Pulpotomies were performed on 72 lower incisors in 24 adult miniature swine. The exposed pulp tissue was treated with EMD or covered with a calcium hydroxide paste $\left(\right.$ Dycal $\left.^{\mathbb{B}}\right)$. At predefined time-points, ranging from 4 days to 12 weeks, experimental teeth were extracted and examined by use of light microscopy, and expression of dentin-related proteins in the pulps was investigated by immunohistochemistry, using antibodies against type I collagen, dentin sialoprotein (DSP), sheathlin, and EMD. In all EMD-treated teeth a substantial amount of reparative dentin formation was observed. The amount of reparative dentin in calcium hydroxide-treated teeth was significantly smaller than in EMD-treated teeth $(P<0.005)$ and was less effective in bridging the pulpal wounds. Immunohistochemistry demonstrated that enamel matrix proteins were present in detectable amounts at the application site for about 4 weeks. Moreover, the expression of proteins related to dentin formation in the wounded pulp tissue was about 2 weeks advanced in EMD-treated teeth. These findings demonstrate that enamel matrix molecules have the capacity to induce rapid pulpal wound healing in pulpotomized teeth, and suggest that the longevity and continued presence of enamel matrix macromolecules at the application site can be utilized to stimulate growth and repair of dentin over a period consistent with a favorable clinical outcome.
\end{abstract}

Key words: Enamel matrix derivative - Pulpal wound healing - Reparative dentin formation - Immunohistochemistry

Trauma, caries, and clinical procedures can all cause exposure of vital pulp tissue that severely hampers the function and lifespan of a tooth. In such cases regener-

Correspondence to: Y. Nakamura; E-mail: yukio@senzoku. showa-u.ac.jp ation of a functional dentin layer that isolates the underlying healthy pulp from the exposure wound would dramatically improve the outcome of restorative procedures. Many strategies have been proposed for effective induction of such dentin bridging, including application of calcium hydroxide [1], and direct capping with composite materials $[2,3]$. Recently, a number of studies have reported that various odontogenic proteins can induce reparative dentin formation. Biologically active molecules, such as the bone morphogenic proteins (BMPs) [4], the osteogenic protein 1 (OP-1) [5], or biomatrices, such as the demineralized dentin [6], have all been proposed to be specific bioinducers of dentin formation. When these substances are brought in close contact with vital pulp tissue they all invariably enhance the normal sequence of morphogenic events in the repairing dental pulp, i.e., rapid fibrodentin matrix formation and subsequent reparative dentinogenesis. However, in many of these studies the cavities were double-sealed with an adhesive resin-based system for final cavity restoration, making it difficult to separate the biological effect(s) from the advantageous effect of a proper cavity sealing $[4,6]$. Furthermore, none of the biomaterials/proteins tested to date are commercially available, nor are their safety and toxicity aspects properly assessed for use in clinical trials.

In early dentin formation during odontogenesis, odontoblasts secrete a unique set of extracellular matrix (ECM) macromolecules comprising essentially type I collagen [7, 8] and some noncollagenous extracellular matrix proteins, i.e., phosphophoryn, dentin matrix protein-1, and dentin sialoprotein (DSP) [9-12]. However, in situ hybridization experiments have revealed that DSP is also transiently expressed by a specific population of preameloblasts at the dentin enamel junction directly before the onset of mantle dentin secretion and mineralization [13]. This transient DSP expression in preameloblasts suggests that DSP might 
have a role in signaling during epithelial-mesenchymal interactions [13]. One other protein suggested to be involved in signaling mechanisms for mesenchymal cell differentiation during odontogenesis, is the recently characterized "sheathlin" [14-19]. Proteins homologous to sheathlin (also named amelin and ameloblastin; Ambn) are present in all other investigated mammalian species including mice [20], rats [21], and humans [22]. All species also show well-conserved DNA sequences and the same differential splicing pattern, suggesting that these proteins have similar important functions during odontogenesis. Moreover, in situ hybridization assays and immunohistochemistry have demonstrated expression of Ambn mRNA and the corresponding proteins at early stages of odontogenesis in pulpal mesenchymal cells as well as in the pre-odontoblasts and in young odontoblasts prior to onset of mantle dentin mineralization [23]. In rats, when the mantle dentin starts to mineralize, the expression of Ambn in odontoblasts gradually fades away. The precise functions of Ambn in dentin formation still remain largely unknown. On the basis of the timing and location of expression $[23,24]$, Ambn could function in extracellular signaling during sequential and reciprocal developmental processes, cell adhesion, and/or act as crystal nucleator during dentin mineralization. Ambn expression has also been demonstrated during trauma-induced reparative dentin formation in adult teeth, suggesting that this protein also is expressed as a part of reparative processes in the dental pulp [25].

Today, ectodermal tooth enamel proteins, in the form of a commercial preparation of porcine fetal enamel matrix derivative $\left(\right.$ Emdogain $^{\circledR}$, Biora AB, Malmö, Sweden), are frequently used in surgical procedures to induce mesenchymal cell differentiation for cementogenesis and periodontal ligament regeneration in patients with advanced periodontitis $[26,27]$. The ability of enamel matrix macromolecules to facilitate regenerative processes in the tooth attachment apparatus is now well recognized in periodontology. Apparently, the enamel matrix derivative (EMD) induces a process that mimics normal odontogenesis, and it is believed that enamel matrix macromolecules participate in the reciprocal ectodermal-mesenchymal signaling and the cell-matrix interactions that control and pattern these processes [28-31]. We have previously demonstrated that EMD can quickly induce large amounts of new, mineralized dentin-like tissue when applied as a direct pulp-capping material onto experimentally exposed pulps of permanent molar teeth in the adult (18 months and older) miniature swine [32]. Moreover, we have shown that EMD can serve as a biologically active pulp dressing agent that specifically induces pulpal wound healing and hard tissue formation in pulpotomized teeth without affecting the normal function of the remaining healthy pulp [33]. Here we use specific antibodies against type I collagen, DSP, and sheathlin (Ambn) to demonstrate by immunohistochemistry, that the new hard tissue induced by EMD truly is dentin, and that the forming of reparative dentin mimics the formation of primary dentin that occurs during odontogenesis. The expression pattern of these markers also demonstrates that the onset of this process is significantly advanced in time when compared with application of calcium hydroxide paste $\left(\right.$ Dycal $\left.{ }^{\circledR}\right)$, a frequently applied and widely accepted pulp-capping material in the clinic today.

Moreover, specific antibodies against EMD are used to demonstrate the presence of the applied enamel proteins at the application site over a biologically significant time-period, and that the induction of reparative dentin formation is spatially and temporally associated with the enamel matrix macromolecules.

\section{Materials and Methods}

\section{Surgical Procedure}

All animal procedures were in accordance with Swedish and European Union regulations and approved by the local experimental animal board and the local ethics committee for animal experiments. A total of 72 permanent lower incisor teeth were used from 24 adult miniature pigs (Göttingen minipig ${ }^{\mathrm{TM}}$, Sus scrofa, Møllegaard, Denmark) with a mean age of 3 years. Animals were divided into seven groups. Observation times were 4 days $(n=4$ teeth/EMD treated, $n=4$ teeth $/ \mathrm{Ca}(\mathrm{OH})_{2}$ treated $), 1$ week $(n=4$ teeth/EMD treated, $n=4$ teeth $/ \mathrm{Ca}(\mathrm{OH})_{2}$ treated $), 2$ weeks $(n=6$ teeth/ EMD treated, $n=6$ teeth $/ \mathrm{Ca}(\mathrm{OH})_{2}$ treated $), 3$ weeks $(n=4$ teeth/EMD treated, $n=4$ teeth/Ca(OH) $)_{2}$ treated), 4 weeks $\left(n=5\right.$ teeth/EMD treated, $n=5$ teeth $/ \mathrm{Ca}(\mathrm{OH})_{2}$ treated $), 8$ weeks $(n=7 \text { teeth/EMD treated, } n=7 \text { teeth/Ca(OH })_{2}$ treated), and 12 weeks $(n=6$ teeth/EMD treated, $n=6$ teeth/ $\mathrm{Ca}(\mathrm{OH})_{2}$ treated), respectively.

The surgical procedures were performed as described by Nakamura et al. [33]. Prior to surgery, animals were anaesthetized with an injection of $10 \mathrm{~mL}$ Ketalar $^{\circledR}$ i.m. and $8 \mathrm{~mL}$ pentobarbital i.v., and the surgical sites were infiltrated with local injections of Xylocain ${ }^{\circledR}(20 \mathrm{mg} / \mathrm{mL})$ and epinephrine $(12.5 \mu \mathrm{g} / \mathrm{mL})$. To facilitate cavity preparation and pulpotomy, the crowns were removed at the gingival cervices using a diamond bur in a high-speed hand piece. Subsequently, the viable pulp tissue was exposed by drilling a cavity in the central part of the tooth using a cylindrical diamond bur, extending about $2 \mathrm{~mm}$ apically from the newly cut occlusal surface. Finally, at the bottom of the prepared cavity, pulpotomy was performed using a sterile, round steel bur, $1 \mathrm{~mm}$ in diameter. About $2 \mathrm{~mm}$ of the pulp tissue beneath the cavity floor was removed, generating a calibrated cylindrical defect of about $2 \times 1 \mathrm{~mm}$ for application of the test material. During all steps of the operative procedure, the tooth and cutting instruments were irrigated with ample amounts of sterile saline. Bleeding was controlled with sterile cotton pellets. The exposed pulp tissue was then covered with EMD (Emdogain ${ }^{\circledR}$ Gel; $30 \mathrm{mg} / \mathrm{mL}$ in propylene-glycol-alginate (PGA); BIORA AB, Malmö, Sweden) or calcium hydroxide (Dycal ${ }^{\circledR}$; DENTSPLY, Konstanz, Germany). All procedures were performed by the same operator. The test materials were applied in a "semi-blinded" fashion, i.e., the test materials were handed to the operator in a random fashion only after the cavity preparation and pulpotomy had been performed. Following the pulp capping, each cavity was immediately sealed with a glass-ionomer cement (GC Fujii II ${ }^{\circledR}$, GC Corporation, Tokyo, Japan). Special care 
was taken to avoid displacement of the test material during the filling procedure.

\section{Enamel Matrix Derivative Formulation}

EMD (Emdogain ${ }^{\circledR}$ Gel, Biora AB) was extracted with acetic acid from nonerupted teeth of 6-month-old domestic female and male pigs. The extract was then purified by ultrafiltration, heat-treated for 3 hours at $80^{\circ} \mathrm{C}$, and filter-sterilized. The purified EMD was mixed with sterile viscous, acidic vehicle PGA to a final concentration of $30 \mathrm{mg} / \mathrm{mL}$ and $\mathrm{pH} 4.5$. At neutral $\mathrm{pH}$ and body temperature, the viscosity decreases and the amelogenin proteins of EMD reassemble into a stable matrix precipitating onto the wound surface.

\section{Histological Examination}

At 4 days and 1, 2, 3, 4, 8, or 12 weeks after surgery the animals were killed by an intracordial bolus injection of $50 \mathrm{~mL}$ sodium pentobarbital in ethanol. After death, experimental teeth were removed in toto, and fixed in cold, $4 \%$ neutral buffered formaldehyde for 24 hours. The teeth were then demineralized in $12.5 \%$ EDTA and subsequently embedded in paraffin. Following longitudinal serial sectioning in $6 \mu \mathrm{m}$ thick sections, every second section was stained with hematoxylin and eosin. Series of hematoxylin and eosin-stained sections containing pulp tissue were then analyzed by using a light microscope equipped for histometry. Unstained sections were used for immunohistochemistry.

\section{Quantitative Analyses of New Hard Tissues}

Quantitative analyses of new hard tissues were measured at 3, 4,8 , and 12 -week observation periods. The amount of new hard tissue formed subjacent to, and within $4 \mathrm{~mm}$ from, the apical margin of the prepared cavity floor, was assessed in the five most central sections from each experimental tooth. Because these sections represent the region with maximal defect width, they cover the central fifth of the defect volume. All other sections were excluded from the histometric analysis to avoid positive bias from anatomical variations of the pulp chamber walls. The areas covered by newly formed hard tissue in these sections were calculated by using digital histometry equipment (Olympus Microimage ${ }^{\circledR}$; Media Cybernetics, Maryland, USA). Mean differences and standard deviations were calculated for the measured variables. Statistical analyses were performed with the statistical program SPSS 10.0 for MS Windows. The Student $t$ test was used to compare the data from EMD-treated and Dycal ${ }^{\mathbb{B}}$-treated groups. A $P$ value below 0.05 was considered to indicate a statistically significant difference between treatments.

\section{Antibodies}

Polyclonal antibodies raised in rabbits against human collagen type I cross-reacting with human, pig, mouse, and rat type I collagen was obtained from Calbiochem, San Diego, CA, USA. Polyclonal antibodies against pig EMD raised in rabbits and purified by affinity chromatography were obtained from Biora AB, Sweden. The rabbit polyclonal anti-rat DSP antibody was raised against DSP peptide (QGLETEGSSTG NKSSITKES) coupled to keyhole limpet hemocyanin (KLH) $[34,35]$. To detect all splice variants of the Ambn gene, four polyclonal antibodies specific for sheathlin were raised in rabbits. Animals were immunized with one of four different polypeptides based on the pig Ambn gene sequence. The amino acid sequences were RPR EHE TQQ YEY SLC CQP QIK RDA WRF QEP, QVA PSE KPP EAE LPG, and CAR GPA GRS RGP PGV. The polypeptides were produced by Eurogentec, Belgium, and purified by reverse phase high-performance liquid chromatography (HPLC). The peptides were coupled to (KLH), emulsified with Freund's complete adjuvant and used for immunization of rabbits (three rabbits for each peptide). After the first immunization, the rabbits were boosted 4 times with the peptide preparations before blood was harvested. The total immunoglobulin ( $\mathrm{IgG}$ ) fraction was purified from the serum by affinity chromatography and HPLC and diluted in phosphate-buffered saline (PBS) to a final concentration of $1 \mathrm{mg} / \mathrm{mL}$.

\section{Western Blot Probing}

To rule out the possibility that the applied EMD preparation contained any molecules that could react with the antibodies used for immunohistochemistry, the EMD preparation was analyzed by Western blot probing using the anti-DSP, antitype I collagen, and anti-sheathlin antibodies. The anti-EMD antibody was included as positive control. EMD from the batch scheduled for application in the animals was diluted to $1.0 \mathrm{mg} / \mathrm{mL}$ in PBS with $0.01 \%$ acetic acid (pH 4.5). The EMD sample were then split into two aliquots and each diluted 1:1 with either nonreducing sodium dodecylsulfate-polyacrylamide gel electrophoresis (SDS-PAGE) sample buffer or reducing SDS-PAGE sample buffer with 5\% beta-mercaptoethanol and heated at $100^{\circ} \mathrm{C}$ for 5 minutes. Samples $(10 \mu \mathrm{L}$ containing $5.0 \mu \mathrm{g}$ of EMD per lane) were subjected to SDSPAGE on $12.5 \%$ Minislab ${ }^{\circledR}$ gel (Bio-Rad Protean II, Hemel, Hempstead, UK). After electrophoresis, the resolved proteins were electroblotted from the gel on to nitrocellulose using a Bio-Rad Mini Transblot apparatus operated at $70 \mathrm{~V}$ for 1 hour. The nitrocellulose was then probed for EMD, DSP, collagen type I, and sheathlin using the rabbit IgG antibodies scheduled for use in the immunohistochemistry assays, in conjunction with an alkaline phosphatase-based immunodetection kit (Bio-Rad) according to the manufacturer's instructions.

\section{Immunohistochemistry}

For immunohistochemistry, the ABC method was used [36]. Sections were deparaffinized and rehydrated, and endogenous peroxidase activity was blocked with $0.3 \%$ hydrogen peroxide in methanol for 20 minutes. To avoid unspecific staining, the sections were incubated with $20 \%$ normal goat serum before the incubation overnight in $4^{\circ} \mathrm{C}$ with primary antibodies, diluted in PBS as follows: anti-EMD 1/1000; anti-DSP 1/200; anti-type I collagen 1/100; and anti-sheathlin mix 1/2000. After being rinsed in PBS, sections were further incubated with biotinylated goat anti-rabbit IgG (Dakopatts AB, Sweden, $1 / 400$ dilution) for 60 minutes, except for anti-EMD stained sections that were incubated with peroxidase conjugated goat anti-rabbit IgG (Dakopatts AB, Sweden, 1/200 dilution). The slides were then rinsed in PBS. Except for the anti-EMD stained slides that were incubated with a peroxidase conjugated secondary antibody, all slides were then treated with ABC-complexes/HRP (Dakopatts AB, Sweden) for $60 \mathrm{~min}-$ utes. Following a final rinsing in PBS, all the sections were incubated with DAB-substrate (Dakopatts AB, Sweden) for 10 to 20 minutes. Directly after DAB incubation, the sections were dehydrated and mounted with Pertex (Histolab, Products AB, Sweden). All dilutions were made in PBS. Negative control sections were treated simultaneously and in a manner identical to that for the test sections except for the primary antibody incubations that were substituted with PBS only.

\section{Results}

\section{Histology}

Four days after pulpotomy and EMD application, a thin, acellular necrotic zone overlaying a minute zone of 

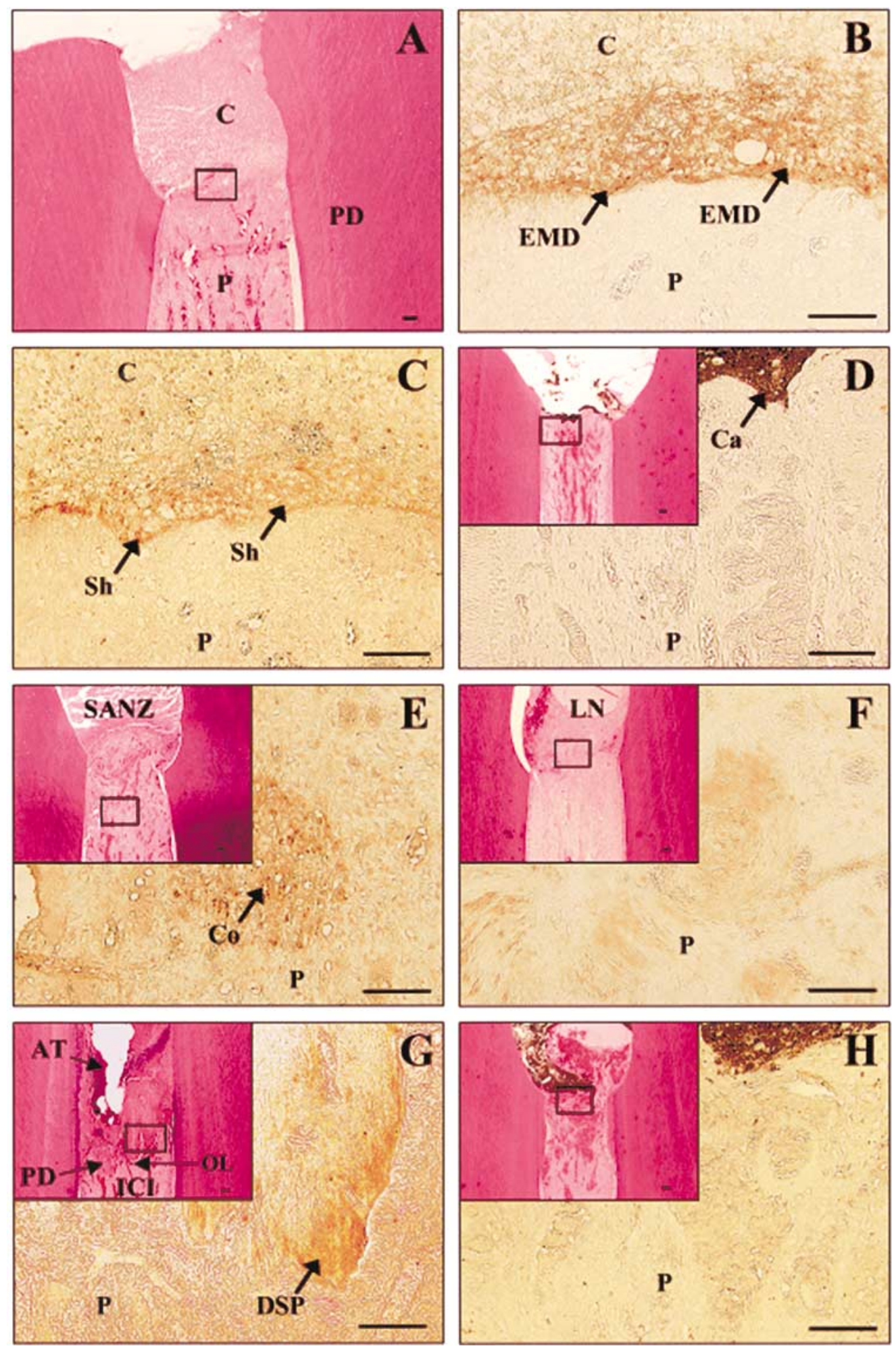

acute inflammation was observed in sections from all EMD-treated teeth. The thin necrotic zone was located at the EMD-pulpal tissue interface, and was clearly distinguishable from the rest of the pulp tissue, delineated by inflammatory cells. Beneath the inflammatory cells, the remaining pulp tissue appeared unaffected by the surgical trauma and the EMD application (Fig. 1A). Following immunohistochemical staining, the thin layer was found to stain positive for anti-EMD (Fig. 1B). At this stage in calcium hydroxide treated teeth, hyperemia and edema of the pulpal tissue with dilated venules were common findings directly subjacent to the calcium 
hydroxide paste (Fig. 1D, inset). However, necrosis and inflammation was not observed in these teeth at this stage.

After one week, all EMD treated teeth exhibited a superficial acellular necrotic zone with an underlying zone of vital pulpal tissue with an acute inflammatory infiltration and dilated venules (Fig. 1E, inset). In calcium hydroxide treated teeth, the corresponding tissue zone was dominated by liquefaction necrosis (Fig. 1F, inset).

At two and three weeks after pulpotomy and EMD application, an acellular tissue overlaying a zone with a slight-to-moderate chronic inflammatory cell infiltrate

Fig. 1. Figures with inserts were prepared from histological sections at 4 days, 1 week, and 3 weeks, respectively. (A) Hematoxylin and eosin-stained micrograph of pulp tissue 4 days after enamel matrix derivative (EMD) application. In the framed area, two clearly distinguished zones can be observed; a superficial layer of necrotic tissue is overlaying a zone of acute inflammation. (B) Micrograph representing frame in (A) showing immunostaining with anti-EMD antibodies revealing the presence of EMD at the application site, below the inflammatory cells in direct contact with the pulp tissue. (C) Micrograph representing frame in (A) showing immunostaining with anti-sheathlin antibodies revealing expression of sheathlin in the superficial pulp tissue 4 days after EMD application. At this early time-point, the expression was observed only adjacent to the amputation site. (D) Picture representing frame in the $\mathrm{H} \& \mathrm{E}$ stained insert showing antisheathlin immunostaining 4 days after calcium hydroxide paste application. Sheathlin was not detected in these teeth at this early stage. The H\&E insert shows edema of the pulp close to the application site with capillaries severely dilated (E) Micrograph representing frame in H\&E stained insert showing immunostaining with anti-type I collagen 1 week after EMD application. Collagen staining was most abundant in central regions of the pulp subjacent to the EMD application, where dentin formation was first observed. (F) Micrograph representing frame in $H \& E$ insert showing immunostaining with anti-type I collagen 1 week after calcium hydroxide application. Some weak, diffuse staining was observed in pulpal connective tissue and close to the dentin walls, but staining was never as localized or abundant as in EMD-treated teeth. (G) Micrograph representing frame in H\&E insert showing immunostaining with anti-DSP 3 weeks after EMD treatment. Expression of DSP was clearly visible in the dentin-like structure forming in the central parts of the pulp wound. (H) Micrograph representing frame in H\&E insert showing immunostaining with anti-DSP 3 weeks after calcium hydroxide application. At this stage no, or only very weak, DSP expression was detected in the pulp. H\&E stained insert shows zones of newly formed predentin along the circumpulpal dentin wall subjacent to the amputation site. Scale bars are $100 \mu \mathrm{m}$. C is the prepared cavity, PD is primary dentin, $\mathrm{P}$ is pulp tissue, EMD is staining with anti-EMD, Sh shows staining with anti-sheathlin, $\mathrm{Ca}$ is calcium hydroxide paste, $\mathrm{Co}$ is staining with anti-type I collagen, SANZ is superficial acellular necrotic zone, LN is liquefaction necrosis, DSP is staining with anti-DSP, AT is acellular tissue, ICI is inflammatory cell infiltration, $\mathrm{PD}$ is predentin, $\mathrm{OL}$ is odontoblast layer. was observed at the pulpal wounds (Fig. 1G inset). Neither signs of irreversible pulp damage nor partial necrosis or infection was observed in EMD-treated teeth at this stage. Also, at this early time, ample amounts of predentin-like tissue were observed forming beneath and along the inflammatory zone, sometimes even completely bridging the cavity. At this stage, in calcium hydroxide paste-treated teeth the situation was dominated by a distinct liquefaction necrosis of the tissue subjacent to the capping material. In most of these teeth, a limited zone of newly formed predentin was observed forming onto and along the circumpulpal dentin wall subjacent to the amputation site (Fig. 1H, inset).

In teeth extracted for sectioning 4 weeks after surgery and EMD application, a web of newly formed islets of reparative dentin in close contact with odontoblast-like cells surrounded the newly formed dentin bridge on the apical side (Fig. 2A). In calcium hydroxide treated teeth extracted at 4 weeks post surgery, new hard tissue resembling reparative dentin forming onto the pulp chamber walls, but not bridging of the cavity, was observed (Fig. 2B). In these teeth the newly formed reparative dentin seemed to form only directly onto and along the pre-existing dentin walls and not along the wound surface.

At eight and twelve weeks following pulpotomy and EMD application, all teeth showed extensive formation of reparative dentin in the form of complete dentin bridges that efficiently sealed off the experimental defects, including the necrotic scab-like tissue and the remaining inflammatory cells (Fig. 2C). At this stage, all calcium hydroxide paste-treated teeth also showed new dentin bridging the cavity. In half of these teeth, the reparative dentin had formed only along the pulp chamber walls (Fig. 2D). In the remaining calcium hydroxide paste-treated teeth, a large amount of hard tissue that extended from the amputation site to the calcium hydroxide-glass-ionomer border was observed. This porous hard tissue sometimes was osteodentin-like with abundant microspaces and marginal gaps of $25 \mu \mathrm{m}$ or more (Fig. 2G and 2H).

In both EMD and Dycal ${ }^{\circledR}$-treated teeth the remaining pulp tissue apical to the newly formed hard tissues appeared healthy with no inflammation present, and there were no signs of internal resorptions, sclerosis, or necrosis (Fig. 2E and 2F).

\section{Quantitative Analyses of Reparative Dentin}

The total amount of newly formed reparative dentin in EMD-treated teeth significantly exceeded $(P<0.005)$ that of calcium hydroxide treated specimens at all observation stages (Fig. 3). When the apical depth of the dentin bridges were assessed 12 weeks after pulpotomy and capping, the mean thickness of the dentin bridging the defects in EMD-treated teeth was more than twice 


\section{Immunohistochemistry}

The results of immunohistochemistry are summarized in Table 2. The strongest anti-EMD staining was seen in sections from teeth of 4 days and of 1 week standing, located at the amputation site as a thin layer directly overlying the pulpal wound. (Figs. 1A, B). After 2 and 3 weeks, the staining was more diffuse and could be observed somewhat deeper in the pulp and at some distance from the wound site. At this stage, the anti-EMD staining often was observed to be concentrated around new capillary vessels growing into the wound area. The anti-EMD staining gradually faded with time, and after 8 to 12 weeks, there were no detectable amounts of EMD left in the pulp tissue or at the application site. In calcium hydroxide paste-treated teeth, no staining with anti-EMD antibodies was observed at any stages. Antisheathlin staining was strongest 4 days after application of EMD (Fig. 1C), but was also clearly visible in teeth of 1 and 2 weeks standing. Anti-sheathlin staining appeared as a thin layer subjacent to or slightly overlapping the EMD layer. The sheathlin expression was associated with a zone of what appeared as traumatized pulp cells along the wound surface, as has previously been demonstrated in traumatized pulp in rats (25). At three weeks, the anti-sheathlin faded and seemed to shift to deeper parts of the wounded pulp. Also the antisheathlin staining weakened gradually over time, and, in 12 -week sections no staining could be observed. In cal-

Fig. 2. Micrographs showing incisor teeth, 4 and 12 weeks after treatment with EMD or calcium hydroxide, respectively. (A) Micrograph of the pulp 4 weeks after application of EMD showing newly formed web of reparative dentin in the central part of the pulp, separating the cavity with the inflammatory infiltrate from the subjacent healthy pulp tissue. (B) Micrograph of pulp tissue 4 weeks after application of calcium hydroxide showing small amounts of reparative dentin forming onto the root canal walls. No bridging was observed in these teeth at this time-point. (C) Micrograph of pulp tissue 12 weeks after application of EMD showing extensive formation of functional reparative dentine completely bridging the experimental defect. The pulp tissue appears healthy with no signs of inflammation or internal resorptions. (D) Micrograph of pulp tissue 12 weeks after application of calcium hydroxide showing complete closure of the pulpal wound. Much reparative dentin can be observed forming onto the pulpal walls causing narrowing of the root pulp chamber. (E) Higher magnification of frame in $(\mathbf{C})$ showing the pulp tissue subjacent to the newly formed dentin. (F) Higher magnification of frame in D) showing the pulp tissue subjacent to the newly formed dentin. (G) Micrograph from a tooth 12 weeks after calcium hydroxide treatment showing extensive dystrophic dentin formation expanding coronally into the cavity space. (H) Higher magnification of frame in $(\mathbf{G})$ showing the porous nature of the dystrophic dentin with "micro holes" and large marginal gaps. Scale bar is $0.5 \mathrm{~mm}(\mathrm{~A}, \mathrm{~B}), 1.0 \mathrm{~mm}(\mathrm{C}, \mathrm{D}, \mathrm{G})$ or $50 \mu \mathrm{m}(\mathrm{E}, \mathrm{F}, \mathrm{H})$. C is the prepared cavity, $\mathrm{PD}$ is primary dentin, $\mathrm{P}$ is pulp tissue, ND is new dentin, gap is marginal gap, $\mathrm{mh}$ is micro holes. All sections are H\&E stained.

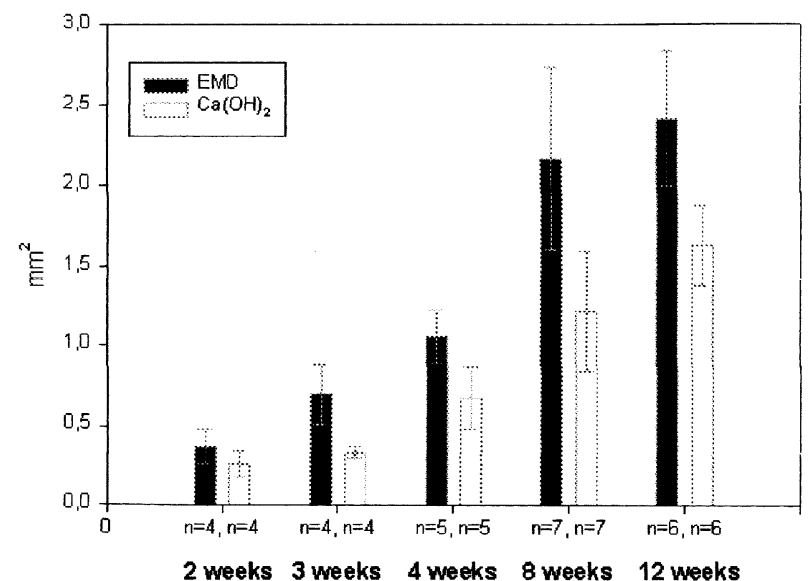

Fig. 3. New dentin area measured by digital histomorphometry. Columns are mean values for defect area covered by new dentin at each time point. Error bars \pm SD.

cium hydroxide paste-treated teeth, no anti-sheathlin staining was observed at 4 days (Fig. 1D) or 1 week. However, after 3 weeks, weak expression of sheathlin could be observed directly subjacent to the visible calcium hydroxide paste at the amputation site. Later this expression shifted to the deeper parts of the wounded pulp, and at 8 and 12 weeks, a weak anti-sheathlin staining could be observed in connection with newly formed reparative dentin-like structures.

Anti-type I collagen staining in the pulpal stroma adjacent to the wound was observed already after 4 days in EMD-treated teeth. This collagen expression was restricted to the amputation site close to the EMD layer (Fig. 1E), but after 1 to 2 weeks after EMD application, the expression seemed to shift to a more diffuse pattern in the deeper parts of the wounded pulp. At 3 weeks, type I collagen expression was mostly concentrated in and around regions where reparative dentin was forming. In calcium hydroxide paste-treated teeth, onset of type I collagen expression was not detected before 1 week after surgery (Fig. 1F). Also, this collagen expression started at the amputation site and then gradually shifted to the deeper parts of the wounded pulp tissue. At 4 weeks, type I collagen expression was most prominent in regions where new dentin was forming.

Anti-DSP expression was not observed until the second week after EMD application. At this stage, DSP expression was visible only in close connection with islets of newly formed dentin-like hard tissue (Fig. 1G). At later stages, anti-DSP staining was clearly detected within the newly formed reparative predentin and dentin. This anti-DSP staining was detectable throughout the observation period for as long as new reparative dentin formation could be observed. In calcium hydroxide paste-treated teeth, the onset of DSP expression was delayed compared to that in EMD- 
Table 1. Quantitative analysis of new hard tissues at 12 weeks

\begin{tabular}{lll}
\hline & EMD $(\mathrm{n}=6)$ & $\mathrm{Ca}(\mathrm{OH})_{2}(\mathrm{n}=6)$ \\
\hline Defect size $(\mathrm{mm})$ & $0.925 \pm 0.2143$ & $0.995 \pm 0.1517$ \\
Complete Dentin bridge & $6 / 6$ & $6 / 6$ \\
Thickness of Dentin bridge $(\mathrm{mm})$ & $1.928 \pm 0.434532^{\mathrm{a}}$ & $0.859 \pm 0.2911$ \\
Dentin area $\left(\mathrm{mm}^{2}\right)$ & $2.419 \pm 0.8438^{\mathrm{b}}$ & $1.628 \pm 0.4956$ \\
\hline
\end{tabular}

${ }^{\mathrm{a}}$ Statistically significant $(P<0.001) ;{ }^{\mathrm{b}}$ Statistically significant $(P<0.005) ; \pm$ is $\mathrm{SD}$

Table 2. Summarized result of immunohistochemistry

\begin{tabular}{|c|c|c|c|c|c|c|c|c|}
\hline \multirow[b]{2}{*}{ Treatment Time } & \multicolumn{2}{|l|}{ Anti-EMD } & \multicolumn{2}{|l|}{ Anti-sheathlin } & \multicolumn{2}{|c|}{ Anti-collagen type I } & \multicolumn{2}{|l|}{ Anti-DSP } \\
\hline & EMD & $\mathrm{Ca}(\mathrm{OH})_{2}$ & EMD & $\mathrm{Ca}(\mathrm{OH})_{2}$ & EMD & $\mathrm{Ca}(\mathrm{OH})_{2}$ & EMD & $\mathrm{Ca}(\mathrm{OH})_{2}$ \\
\hline 4 days & +++ Fig. 1B & NA & ++ Fig. $1 \mathrm{C}$ & - Fig. 1D & + & $+1-$ & - & - \\
\hline 1 week & +++ & NA & ++ & - & ++ Fig. 1E & + Fig. 1F & - & - \\
\hline 2 weeks & ++ & NA & ++ & $+1-$ & +++ & ++ & $+/-$ & - \\
\hline 3 weeks & + & NA & + & ++ & +++ & ++ & ++ Fig. $1 G$ & - Fig. $1 \mathrm{H}$ \\
\hline 4 weeks & $+/-$ & NA & + & ++ & +++ & +++ & ++ & + \\
\hline 8 weeks & - & NA & + & ++ & +++ & +++ & ++ & ++ \\
\hline 12 weeks & - & NA & - & + & +++ & +++ & + & + \\
\hline
\end{tabular}

NA is not analyzed; - is no detectable immunostaining; $+/-$ is weak immunostaining; + is moderate immunostaining; ++ is moderate to strong immunostaining; +++ is strong immunostaining

treated teeth, not commencing earlier than 4 weeks (Fig. 1H), but lasting throughout the remainder of the observation period. The staining pattern, however, was similar to that observed for EMD-treated teeth.

\section{Discussion}

The purpose of the present study was to characterize the efficiency and nature of EMD-induced reparative hard tissue formation in experimental pulpal wounds. When wounded pulp tissue is exposed to EMD, a substantial amount of reparative dentin tissue can be demonstrated forming close to the application site. This reparative process first resembles a classic wound-healing including the formation of a scab and a moderate inflammatory infiltrate beneath the injury. Subsequently, neogenesis of normal pulp tissue and dentin formation occur; after the initial healing phase, a fine web of reparative dentin structures encircled by odontoblast-like cells is observed growing from the central parts of the pulp and outward against the pulp chamber walls. This early EMD-induced hard tissue mostly resembles osteodentin; however, before 4 weeks, the morphologic characteristics of new hard tissue changes toward normal looking reparative dentin with abutting odontoblasts and inserted tubules.

In contrast, calcium hydroxide paste treatment immediately causes pulpal liquefaction necrosis at the application site, with no signs of increased cellular activity in the adjacent tissues. Four weeks later, a new layer of hard tissue can be observed forming onto the dentinal walls subjacent to the application site. At this stage, new blood vessels forming close to the pre-existing odontoblasts suggest an increased activity in these cells. The hard tissue forming in calcium hydroxide pastetreated teeth resembles secondary dentin from the beginning of the reparative process, and no intermediate osteodentin stage was observed. Furthermore, because the new dentin forms only onto the pre-existing dentin walls, dentin formation in calcium hydroxide pastetreated teeth causes narrowing of the root canal with subsequent displacement of the viable pulp tissue. Several of the calcium hydroxide paste-treated teeth also exhibited huge dysplastic, porous hard-tissue structures with marginal gaps extending from the pulp tissue and into the calcium hydroxide filled space. Such structures have previously been described as "microhole"-like defects [37] or tunnel defects [38], and are believed to be the prime reason for the frequent failure of calcium hydroxide promoted dentin formation to seal off wounded pulp tissue from infectious and/or cytotoxic agents.

The differences in appearance of the observed reparative processes suggest that the modus operandi for EMD and calcium hydroxide promoted dentin formation is fundamentally distinct. EMD seems to induce dentin formation by way of new odontoblastic cells recruited from the central parts of the dental pulp. The origin of these mesenchymal cells remains unknown, but it is believed that they are derived from pulpal stem cells or resting (pre-)odontoblasts, which are an intrinsic part 
of the pulpal repair mechanism $[25,39,40]$. Calcium hydroxide treatment, on the other hand, seems to cause a superficial sterile necrosis resembling a chemical burn, that in turn mostly promotes dentin formation by preexisting, mature odontoblasts already positioned at the dentin walls at the time of wounding.

The molecular mechanism(s) underlying induction of dentin formation by EMD is not understood in detail. However, it has been reported that EMD induces an intracellular cyclic-AMP signal in mesenchymal cells. This intracellular signal is followed by autocrine secretion of growth factors from EMD stimulated cells with subsequent differentiation into extracellular matrix secreting cells [30]. Furthermore, EMD has been shown to induce in cultured fibroblasts the expression of specific integrins known to play important roles in mesenchymal cell attachment, development, and function [31, 41]. In the present study, we demonstrate, using immunohistochemistry with highly specific antibodies, that immunogenically intact, and thus presumably active, EMD remains at the application site for more than 3 weeks after application. During this time, proteins associated with dentinogenesis seemed to be sequentially expressed by cells in the wounded pulp tissue. Notably, expression of sheathlin was detected in pulpal cells in the wound area already 4 days after EMD application. This is in accordance with earlier findings in rats, that show rapid expression of ameloblastin (Ambn) following trauma-induced damage to the odontoblastic cell layer [25]. In calcium hydroxide-treated teeth, however, weak sheathlin expression was delayed until 3 weeks after wounding. However, in all experimental teeth, the expression of sheathlin preceded new dentin formation. A close time relationship between amelin (the rat homolog to sheathlin) expression and reparative dentin formation has also been observed by Spahr et al. [25] in trauma-induced dentinogenesis in rats. These findings suggest that sheathlin/amelin is part of a signal pathway for induction of reparative dentin formation, and that in adult teeth, this signal can be enhanced by application of enamel matrix macromolecules.

The new hard tissue that formed following EMD application also stained positive for type I collagen and DSP. Together these two proteins are regarded as dentin specific markers [8], confirming that the composition as well as the morphology of the newly formed hard tissue resembles ordinary dentin. This is also true for the new dentin forming in calcium hydroxide-treated teeth, albeit here the onset of expression of these marker molecules was delayed by about 2 weeks relative to EMDtreated teeth.

The present study clearly demonstrates a potential for EMD as a rapid biological inducer for wound healing and dentin formation in pulpotomized teeth. Also, considering its stability, continued presence at the application site, and reported antibacterial effect [42], we conclude that EMD provides a beneficial environment for pulpal reparative processes in traumatized teeth.

Further characterization of the EMD components and their role in mineralizing tissue formation and repair may shed new light on the formation of dental tissues and pave the road for development of new, extracellular matrix-based therapeutic strategies that mimic natural developmental processes and enhance the regenerative capacity of adult tissues.

Acknowledgments. The authors gratefully acknowledge Professor Lars Hammarström for his valuable and stimulating discussions and constructive criticism during this work. The authors also would like to thank Eva Lundberg, Helena Ekdahl, and Ulla-Britt Carlsson for excellent assistance during the animal and laboratory procedures, and Beata Fabi for her kind help with preparing figures. The work was supported by the EU grant QLK3-CT-2001-00090.

\section{References}

1. Ranly DM, Garcia-Godoy F (2000) Current and potential pulp therapies for primary and young permanent teeth. $\mathbf{J}$ Dent 28:153-161

2. Cox CF, White KC, Ramus DL, Farmer JB, Snuggs HM (1992) Reparative dentin: factors affecting its deposition. Quintessence Int 23:257-270

3. Shumayrikh NM, Adenubi JO (1999) Clinical evaluation of glutaraldehyde with calcium hydroxide and glutaraldehyde with zinc oxide eugenol in pulpotomy of primary molars. Endod Dent Traumatol 15:259-264

4. Nakashima M (1994) Induction of dentin formation on canine amputated pulp by recombinant human bone morphogenetic proteins (BMP)-2 and -4. J Dent Res 73:1515-1522

5. Rutherford RB, Wahle J, Tucker M, Rueger D, Charette $M$ (1993) Induction of reparative dentin formation in monkeys by recombinant human osteogenic protein-1. Arch Oral Biol 38:571-576

6. Nakashima M (1989) Dentin induction by implants of autolyzed antigen-extracted allogeneic dentin on amputated pulps of dogs. Endo Dent Traumatol 5:279-286

7. Bronckers AL, Lyaruu DM, Woltgens JH (1989) Immunohistochemistry of extracellular matrix proteins during various stages of dentinogenesis. Connect Tissue Res 22:65-70

8. Butler WT (1995) Dentin matrix proteins and dentinogenesis. Connect Tissue Res 33:59-65

9. Butler WT, Ritchie H (1995) The nature and functional significance of dentin extracellular matrix proteins. Int $\mathbf{J}$ Dev Biol 39:169-179

10. Macdougall M, Gu TT, Luan X, Simmons D, Chen J (1998) Identification of a novel isoform of mouse dentin matrix protein 1: spatial expression in mineralized tissues. J Bone Miner Res 13:422-431

11. Ritchie HH, Hou H, Veis A, Butler WT (1994) Cloning and sequence determination of rat dentin sialoprotein, a novel dentin protein. J Biol Chem 269:3698-3702

12. Qin C, Brunn JC, Cadena E, Ridall A, Tsujigiwa H, et al. (2002) The expression of dentin sialophosphoprotein gene in bone. J Dent Res 8:392-394

13. Ritchie HH, Berry JE, Somerman MJ, Hanks CT, Bronckers AL, et al. (1997) Dentin sialoprotein (DSP) transcripts: developmentally-sustained expression in odontoblasts and transient expression in pre-ameloblasts. Eur J Oral Sci 105:405-413

14. Hu CC, Fukae M, Uchida T, Qian Q, Zhang CH, et al. (1997) Sheathlin: cloning, cDNA/polypeptide sequences, 
and immunolocalization of porcine enamel sheath proteins. J Dent Res 76:648-657

15. Uchida T, Murakami C, Wakida K, Dohi N, Iwai Y, et al. (1998) Sheath proteins: synthesis, secretion, degradation and fate in forming enamel. Euro $\mathbf{J}$ Oral Sci 106:308-314

16. Cerny R, Slaby I, Hammarström L, Wurtz T (1996) A novel gene expressed in rat ameloblasts codes for proteins with cell binding domains. J Bone Miner Res 11:883-891

17. Krebsbach PH, Lee SK, Matsuki Y, Kozak CA, Yamada KM, et al. (1996) Full-length sequence, localization, and chromosomal mapping of ameloblastin. A novel toothspecific gene. J Biol Chem 271:4431-4435

18. Lee SK, Krebsbach PH, Matsuki Y, Nanci A, Yamada KM, et al. (1996) Ameloblastin expression in rat incisors and human tooth germs. Int J Dev Biol 40:1141-1150

19. Uchida T, Murakami C, Dohi N, Wakida K, Satoda T, et al. (1997) Synthesis, secretion, degradation, and fate of ameloblastin during the matrix formation stage of the rat incisor as shown by immunocytochemistry and immunochemistry using region-specific antibodies. J Histochem Cytochem 45:1329-1340

20. Simmons D, Gu TT, Krebsbach PH, Yamada Y, Macdougall M (1998) Identification and characterization of a cDNA for mouse ameloblastin. Connect Tissue Res 39:3-12

21. Bleicher F, Couble ML, Farges JC, Couble P, Magloire H (1999) Sequential expression of matrix protein genes in developing rat teeth. Matrix Biol 18:133-143

22. Macdougall M, Simmons D, Gu TT, Forsman-semb K, Mardh CK, et al. (2000) Cloning, characterization and immunolocalization of human ameloblastin. Eur J Oral Sci 108:303-310

23. Fong CD, Slaby I, Hammarström L (1996) Amelin: an enamel-related protein, transcribed in the cells of epithelial root sheath. J Bone Miner Res 11:892-898

24. Begue-kirn C, Krebsbach PH, Bartlett JD, Butler WT (1998) Dentin sialoprotein, dentin phosphoprotein, enamelysin and ameloblastin: tooth-specific molecules that are distinctively expressed during murine dental differentiation. Eur J Oral Sci 106:963-970

25. Spahr A, Lyngstadaas SP, Slaby I, Haller B, Boeckh C, et al. (2002) Expression of amelin and trauma-induced dentin formation. Clin Oral Investig. 6:51-57

26. Heijl L, Heden G, Svärdström G, Ostgren A (1997) Enamel matrix derivative (EMDOGAIN) in the treatment of intrabony periodontal defects. J Clin Periodontol 24:705714

27. Pontoriero R, Wennstrom J, Lindhe J (1999) The use of barrier membranes and enamel matrix proteins in the treatment of angular bone defects. A prospective controlled clinical study. J Clin Periodontol 26:833-840
28. Hammarström L (1997) Enamel matrix, cementum development and regeneration. J Clin Periodontol 24:658-668

29. Hammarström L, Heijl L, Gestrelius S (1997) Periodontal regeneration in a buccal dehiscence model in monkeys after application of enamel matrix proteins. J Clin Periodontol 24:669-667

30. Lyngstadaas SP, Lundberg E, Ekdahl H, Andersson C, Gestrelius S (2001) Autocrine growth factors in human periodontal ligament cells cultured on enamel matrix derivative. J Clin Periodontol 28:181-188

31. Hoang AM, Klebe RJ, Steffensen B, Ryu OH, Simmer JP, et al. (2002) Amelogenin is a cell adhesion protein. J Dent Res 81:497-500

32. Nakamura Y, Hammarström L, Lundberg E, Ekdahl H, Matsumoto K, et al. (2001) Enamel matrix derivative promotes reparative processes in the dental pulp. Adv Dent Res 15:105-107

33. Nakamura Y, Hammarström L, Matsumoto K, Lyngstadaas SP (2002) The induction of reparative dentin by enamel proteins. Int Endo J 35:407-417

34. Ritchie HH, Wang L-H (1998) The expression of DSP protein from a baculovirus construct containing rat DSPPP cDNA. J Dent Res. 77:157

35. Ittersum JV, Ritchie HH (2002) Post-translational analysis of rat dentin phosphophoryn from dentin matrix and a DSP-PP construct. J Dent Res 81:A278

36. Hsu SM, Raine L, Fanger H (1981) Use of avidin-biotinperoxidase complex (ABC) in immunoperoxidase techniques: a comparison between $\mathrm{ABC}$ and unlabeled antibody (PAP) procedures. J Histochem Cytochem 29: 577-580

37. Goldberg F, Massone EJ, Spielberg C (1984) Evaluation of the dentinal bridge after pulpotomy and calcium hydroxide dressing. J Endo 10:318-320

38. Cox CF, Subay RK, Ostro E, Suzuki S, Suzuki SH (1996) Tunnel defects in dentin bridges: their formation following direct pulp capping. Oper Dent 21:4-11

39. Thesleff I, Tummers M (2003) Stem cells and tissue engineering: prospects for regenerating tissues in dental practice. Med Princ Pract 12(Suppl 1):43-50

40. Miura M, Gronthos S, Zhao M, Lu B, Fisher LW, et al. (2003) Stem cells from human exfoliated deciduous teeth. Proc Natl Acad Sci U S A 100:5807-5812

41. van der Pauw MT, Everts V, Beertsen W (2002) Expression of integrins by human periodontal ligament and gingival fibroblasts and their involvement in fibroblast adhesion to enamel matrix-derived proteins. J Periodontal Res 37:317-323

42. Spahr A, Lyngstadaas SP, Boeckh C, Andersson C, Podbielski A, et al. (2002) Effect of the enamel matrix derivative Emdogain on the growth of periodontal pathogens in vitro. J Clin Periodontol 29:62-72 